\title{
Optimizing the Risk Assessment in Upper Gastrointestinal Bleeding: Comparison of 5 Scores Predicting 7 Outcomes
}

\author{
Tiago Cúrdia Gonçalves ${ }^{\mathrm{a}-\mathrm{c}}$ Mara Barbosa $^{\mathrm{a}-\mathrm{c}}$ Sofia Xavier ${ }^{\mathrm{a}-\mathrm{c}}$ \\ Pedro Boal Carvalho ${ }^{\mathrm{a}-\mathrm{c}}$ João Firmino Machado ${ }^{\mathrm{d}}$ Joana Magalhães ${ }^{\mathrm{a}-\mathrm{c}}$ \\ Carla Marinho $^{\mathrm{a}-\mathrm{c}}$ José Cotter ${ }^{\mathrm{a}-\mathrm{c}}$ \\ ${ }^{a}$ Gastroenterology Department, Hospital da Senhora da Oliveira, Guimarães, Portugal; ${ }^{b}$ Life and Health Sciences \\ Research Institute, School of Medicine, University of Minho, Braga, Portugal; ' $I$ ICVS/3B's, PT Government Associate \\ Laboratory, Braga/Guimarães, Portugal; ${ }^{d}$ Unidade de Saúde Pública Porto Ocidental, Porto, Portugal
}

\section{Keywords}

Upper gastrointestinal bleeding $\cdot$ Risk assessment $\cdot$ Scores . Outcomes

\section{Abstract}

Introduction: Although different scores have been suggested to predict outcomes in the setting of upper gastrointestinal bleeding (UGIB), few comparative studies between simplified versions of older scores and recent scores have been published. We aimed to evaluate the accuracy of pre- (PreRS) and postendoscopic Rockall scores (PostRS), the GlasgowBlatchford score (GBS) and its simplified version (sGBS), as well as the AIMS65 score in predicting different clinical outcomes. Methods: In this retrospective study, PreRS, PostRS, GBS, sGBS, and AIMS65 score were calculated, and then, areas under the receiver operating characteristic curve were used to evaluate the performance of each score to predict blood transfusion, endoscopic therapy, surgery, admission to intensive/intermediate care unit, length of hospital stay, as well as 30-day rebleeding or mortality. Results: PreRS, PostRS, GBS, and sGBS were calculated for all the 433 included patients, but AIMS65 calculation was only possible for 315 patients. Only the PreRS and PostRS were able to fairly pre- dict 30-day mortality. The GBS and sGBS were good in predicting blood transfusion and reasonable in predicting surgery. None of the studied scores were good in predicting the need for endoscopic therapy, admission to intensive/intermediate care unit, length of hospital stay, and 30-day rebleeding. Conclusions: Owing to the identified limitations, none of the 5 studied scores could be singly used to predict all the clinically relevant outcomes in the setting of UGIB. The sGBS was as precise as the GBS in predicting blood transfusion and surgery. The PreRS and PostRS were the only scores that could predict 30-day mortality. An algorithm using the PreRS and the sGBS as an initial approach to patients with UGIB is presented and suggested.

(c) 2018 Sociedade Portuguesa de Gastrenterologia Published by S. Karger AG, Basel

\section{Otimização da abordagem do risco na hemorragia digestiva alta: comparação de cinco scores na predição de sete outcomes}

\section{Palavras Chave}

Hemorragia digestiva alta · Avaliação do risco · Scores · Outcomes

\section{KARGER}

E-Mail karger@karger.com www.karger.com/pjg
(C) 2018 Sociedade Portuguesa de Gastrenterologia Published by S. Karger AG, Basel

Karcer

Open access

This article is licensed under the Creative Commons AttributionNonCommercial-NoDerivatives 4.0 International License (CC BYNC-ND) (http://www.karger.com/Services/OpenAccessLicense). Usage and distribution for commercial purposes as well as any distribution of modified material requires written permission.
Dr. Tiago Cúrdia Gonçalves

Gastroenterology Department, Hospital da Senhora da Oliveira

Rua dos Cutileiros, Creixomil

PT-4835-044 Guimarães (Portugal)

E-Mail tiagogoncalves@ hospitaldeguimaraes.min-saude.pt 


\section{Resumo}

Introdução: Apesar dos vários scores propostos para prever os diferentes outcomes no contexto de hemorragia digestiva alta (HDA), poucos estudos se debruçaram sobre a comparação entre eles. Este estudo avaliou o desempenho dos scores de Rockall pré- (PreRS) e pós-endoscópico (PosRS), Glasgow-Blatchford (GBS) e a sua versão simplificada (sGBS), bem como o score AIMS65 na previsão de diferentes outcomes clínicos. Métodos: Neste estudo retrospetivo, foram calculados os scores PreRS, PosRS, GBS, sGBS e AIMS65 e posteriormente as respectivas áreas sob as curvas de ROC para avaliar a capacidade de cada score em predizer necessidade de suporte transfusional, terapêutica endoscópica, cirurgia, admissão em unidade de cuidados intensivos/intermédios, tempo de internamento, bem como recidiva hemorrágica ou morte aos 30 dias. Resultados: Em todos os 433 doentes incluídos foram calculados os scores PreRS, PosRS, GBS, sGBS, mas o cálculo do score AIMS65 apenas foi possível em 315 doentes. Apenas o PreRS e o PosRS foram capazes de prever de forma aceitável a mortalidade aos 30 dias. O GBS e o sGBS apresentaram uma boa capacidade de prever necessidade de transfusão e razoável capacidade para prever cirurgia. Nenhum dos cinco scores foi bom a predizer a necessidade de tratamento endoscópico, internamento em unidade de cuidados intensivos/intermédios, tempo de internamento ou recidiva hemorrágica aos 30 dias. Conclusões: Devido às limitações identificadas, nenhum dos scores pode ser usado isoladamente na previsão dos diferentes outcomes no contexto de HDA. O sGBS é tão preciso como o GBS na previsão da necessidade de transfusão ou cirurgia. Apenas os scores PreRS e PosRS são capazes de prever mortalidade aos 30 dias. É sugerido um algoritmo para a abordagem inicial de doentes com HDA usando os scores PreRS e sGBS.

(c) 2018 Sociedade Portuguesa de Gastrenterologia Publicado por S. Karger AG, Basel

\section{Introduction}

Upper gastrointestinal bleeding (UGIB) is a common, potentially life-threatening condition and remains the most common medical emergency managed by gastroenterologists. It has an incidence of about 100 per 100,000 adults per year, accounts for more than 300,000 annual hospital admissions in the United States, and can result in death in up to $15 \%$ of the cases [1-3].

Recent guidelines recommend risk assessment as an initial step in the management of patients with UGIB for early stratification of low- and high-risk patients, allow- ing timely and appropriate interventions, which may consequently decrease morbidity and mortality [4]. With adequate risk assessment tools, it is possible not only to predict which patients are at risk of adverse events, such as rebleeding or death, but also to guide management decisions, such as time to endoscopy, length of hospital stay, and level of care [5].

Several prognostic and risk scoring systems, such as the Rockall score (RS) [6], the Glasgow-Blatchford score (GBS) [7], and the AIMS65 score [8], have been developed to predict outcomes in the UGIB setting. The RS is one of the most commonly cited scores, which includes a clinical and an endoscopic component, and has been originally suggested as a tool to predict mortality [6]. Some years later, the GBS was established as an instrument to evaluate the need for medical intervention (i.e., blood transfusion, therapeutic endoscopy or surgery), without including endoscopic data [7]. Yet, as this score contains some subjective components that may preclude its accurate use, a modified version has been recently published [9]. Additionally, the AIMS65 is another modern and simpler risk score, composed of easy-access parameters, which was created with the aim to increase adherence to risk stratification and to facilitate earlier triage and goal-directed treatment [8].

As UGIB is a medical emergency requiring timely decisions, it is important that physicians know exactly which risk scores are reliable for each clinical outcome. However, with the advent of new scores and variations of older ones, that task can be time-consuming, leading to poor adherence to risk stratification in the routine clinical practice.

The aim of this study was to compare 5 different risk scores used to evaluate patients presenting with UGIB, namely to assess their performance in predicting 7 different clinical outcomes: admission to intensive or intermediate care unit, blood transfusion, endoscopic therapeutic intervention, surgical treatment, length of hospital stay, and 30-day rebleeding and mortality.

\section{Methods}

Study Design and Patients' Selection

Data from adult nontrauma outpatients who consecutively presented to the emergency department (ED) of our center for UGIB and received endoscopic evaluation between January 1, 2012, and December 31, 2015, were retrospectively collected. UGIB was defined as hematemesis, "coffee-ground" vomit, melena, hematochezia with suspected bleeding from the upper gastrointestinal tract or detection of coffee-ground-like substance, or blood from a nasogastric tube. All UGIB cases were included, in- 
dependently of the bleeding source (variceal or nonvariceal). Patients younger than 18 years old, whose source of bleeding was the lower or middle gastrointestinal tract, who received any treatment at another institution, or who visited the ED due to rebleeding from a previous UGIB episode were excluded from this study. The study was approved by the local ethics committee. Since the study was retrospective and the study subjects were anonymized, the ethical committee waived the necessity for written consent from the patients.

\section{Analyzed Variables}

Data were collected from medical records and included patients' age and gender, type of presentation of bleeding, history of syncope, comorbidities (namely hepatic disease, cardiac failure, ischemic heart disease, renal failure, disseminated neoplasia, or any other major comorbidity), vital signs and mental status at admission, and laboratory values (i.e., hemoglobin, urea, albumin, and international normalized ratio [INR]). When multiple vital signs or laboratory tests were available from the ED, the most anomalous values were collected. Endoscopic diagnosis, stigmata of recent bleeding, and length of hospital stay were also included in the database. Similarly to other studies, hepatic disease was considered when patients had known history, or clinical and laboratorial evidence, of chronic or acute liver disease, while heart failure was defined as known history, or clinical and echocardiographic evidence, of cardiac failure [10]. Ischemic heart disease was said to be present if there was a past history of myocardial infarction, stable and unstable angina, or coronary intervention. Renal failure was defined as patients with an estimated glomerular filtration rate $<60 \mathrm{~mL} / \mathrm{min}$ for $\geq 3$ months calculated using the Modification of Diet in Renal Disease Study equation. Disseminated neoplasia was considered in patients who have cancer that has spread to one or more sites in addition to the primary site or in whom the presence of metastases suggests that cancer is widespread, fulminant, or near terminal. Altered mental status was defined as Glasgow Coma Scale of $\leq 14$ or a physician-charted designation of "disoriented," "lethargy," "stupor," or "coma" [8].

\section{Scores in UGIB}

In this study, 5 different proposed scores used for the evaluation of patients with UGIB were compared. The pre-endoscopic or clinical RS (PreRS) includes age, presence of shock, and comorbidities to stratify patients from 0 to 7 points. This score can be further complemented with endoscopic data, namely endoscopic diagnosis and stigmata of recent hemorrhage, resulting in the postendoscopic or complete RS (PostRS), which scores patients with a maximum of 11 points (Table 1). The GBS includes only clinical and laboratory but not endoscopic variables, while the simplified GBS (sGBS) avoids the subjective or difficult-to-define components of the original GBS, namely melena, syncope, hepatic disease, or heart failure (Table 1) [9]. The GBS and sGBS are scored up to 23 or 16 points, respectively. The AIMS65 comprises 5 clinical and laboratorial parameters, each corresponding to 1 point (Table 1). As serum albumin is a laboratory parameter that is not always ordered when patients are being evaluated in the ED, the calculation of the AIMS65 score was only possible in 315 patients.

\section{Clinical Outcomes}

During hospitalization, clinical outcomes, such as blood transfusion, therapeutic endoscopic intervention, admission in inter- mediate or intensive care unit, length of stay, and surgery, were analyzed. The decision of transfusion was made by the attending physician, following local ED transfusion protocols. Therapeutic endoscopic intervention included one or more of the following hemostatic strategies: use of hemoclips, argon plasma coagulation, endoscopic band ligation, sclerotherapy, cyanoacrylate injection, or multipolar electrocoagulation, with or without previous injection of epinephrine. Length of hospital stay was divided into short and long, when patients were admitted for $<7$ or $\geq 7$ days, respectively. Need for surgery was defined as the need to undergo laparotomy after the first or second endoscopy had failed to secure the UGIB episode. After discharge, patients were referred to the outpatient clinics and were followed up for a minimum of 30 days. During the follow-up, 30-day rebleeding and mortality were evaluated. Rebleeding was defined as recurrent hematemesis, melena, or both with either shock or a decrease in hemoglobin of at least $2 \mathrm{~g} / \mathrm{dL}$ after initial treatment and stabilization. Mortality was defined as death occurring within 30 days of hospital admission.

\section{Statistical Analysis}

Descriptive analysis of the results was performed using the Statistical Package for the Social Sciences (SPSS) software, version 22.0 (IBM, Armonk, NY, USA). Continuous variables were expressed as means \pm standard deviations or medians and interquartile ranges (IQR), when normal or non-normal distributions of data were found, respectively. Categorical variables were expressed as absolute frequency (number) and relative frequency (percentages). The accuracy of each risk score to predict clinical outcomes was evaluated by the area under the receiver operating characteristic (AUROC) curve with 95\% confidence interval (CI). An AUROC of $0.9-1$ indicates an excellent predictive power, while an AUROC of $0.8-0.9,0.7-0.8,0.6-0.7$, and $0.5-0.6$ represent good, fair, poor, and failed predictive power, respectively. Comparison of different scores' prognostic accuracy was performed using the method described by Hanley and McNeil [11]. In each curve, Youden index $J$, the point on the ROC curve that is farthest from the line of equality (diagonal line), is represented. A $p$ value of 0.05 was considered statistically significant.

\section{Results}

\section{Characterization of Patients and UGIB Episodes}

During the studied period of time, a total of 433 episodes of UGIB were identified and selected for analysis. Almost two-thirds (64.9\%) of the patients were male, and the median age was 67.8 years (IQR: 56.0-80.0). At admission, melena alone was the most common presentation of UGIB (in $46.2 \%$ patients), while hematochezia was rare $(2.8 \%)$. Syncope was reported by about one-tenth of patients. Heart failure and liver disease were the most common comorbidities, being present in 21.9 and $19.6 \%$ of the patients, respectively. Regarding medication, more than one-fourth of the patients (27.5\%) were taking proton pump inhibitors when the bleeding episode occurred. Acetylsalicylic acid, nonsteroidal anti-inflammatory drugs, anticoagulants, and other 
Table 1. Rockall score, Glasgow-Blatchford score, AIMS65 score, and respective variables

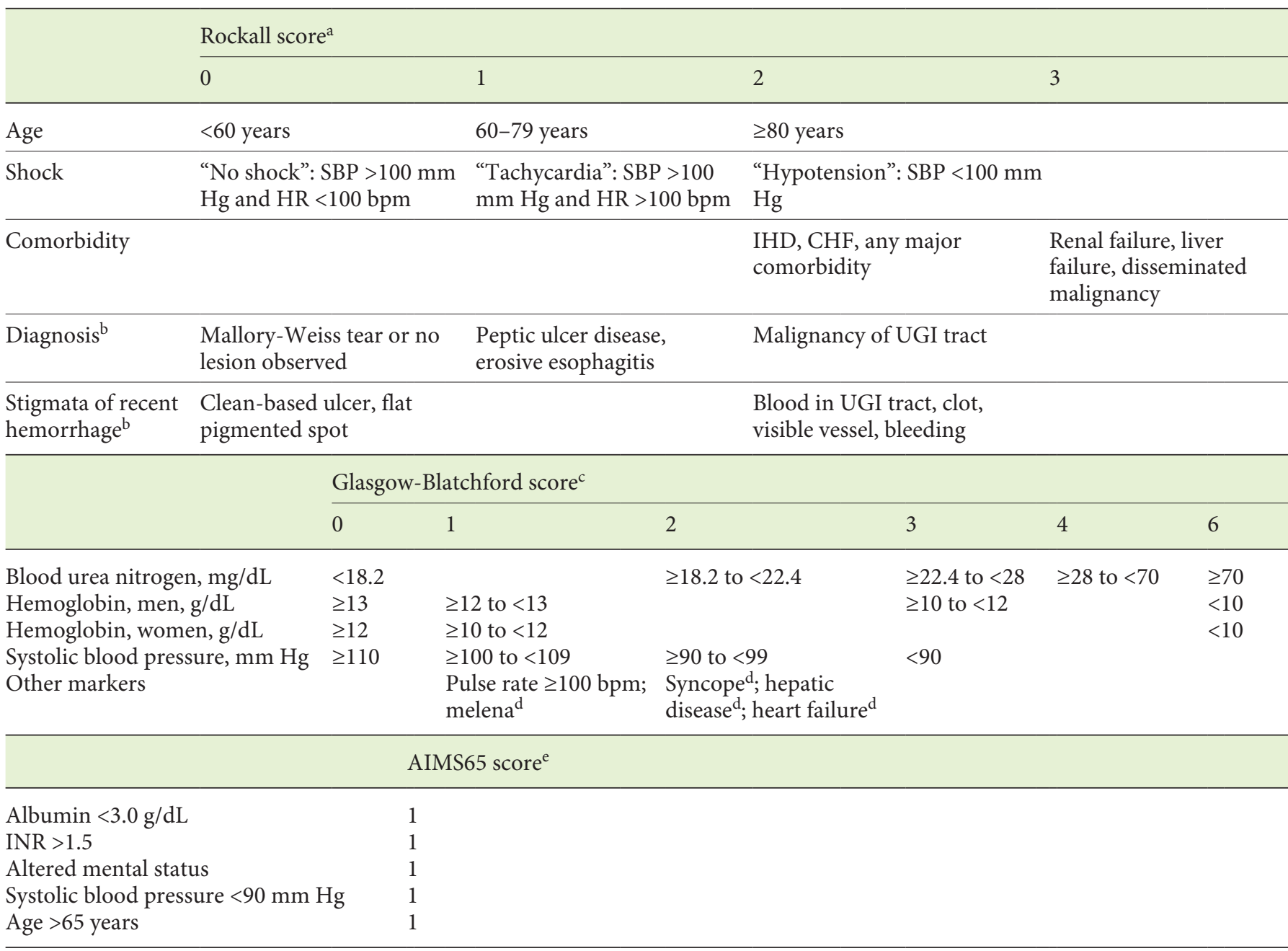

SBP, systolic blood pressure; HR, heart rate; bpm, beats per minute; IHD, ischemic heart disease; CHF, congestive heart failure; UGI, upper gastrointestinal; INR, international normalized ratio. ${ }^{\text {a }}$ Maximum score in the postendoscopic Rockall score: 11 points; maximum score in the pre-endoscopic Rockall score: 7 points. ${ }^{b}$ Variables not included in the pre-endoscopic Rockall Score. ${ }^{\mathrm{c}}$ Maximum score in the original Glasgow-Blatchford score: 23 points; maximum score in the modified Glasgow-Blatchford score: 16 points. ${ }^{\mathrm{d}}$ Variables not included in the simplified Glasgow-Blatchford score. ${ }^{\mathrm{e}}$ Maximum score: 5 points.

antiplatelet agents were used in $27.7,17.3,17.3$, and $10.4 \%$, respectively. Patients presenting with tachycardia were common (in 26.6\%), but hypovolemic shock was present in only $16.4 \%$ of the cases. Laboratory results and detailed patient characteristics are shown in Table 2.

After upper endoscopy, the 3 most frequent sources of bleeding were gastric ulcers, esophageal varices, and duodenal ulcers, accounting for $16.9,15.2$, and $14.8 \%$ of the endoscopic diagnosis, respectively. Upper endoscopy was unrevealing in almost one-fifth (17.8\%) of the patients. A full list of endoscopic findings and respective frequencies can be found in Table 2 .

\section{Risk Score Calculation and Distribution}

Using the collected data, the 5 risk scores described in the Methods section were calculated. Data for the calculation of the PreRS and PostRS were available for all patients. The mean calculated PreRS was $3.3 \pm 1.6$, while the PostRS was $4.4 \pm 1.8$. Calculation of the GBS and sGBS was possible in all patients as well. The mean values were $11.6 \pm 3.7$ for the GBS and $10.0 \pm 3.3$ for the sGBS. The mean value of the AIMS65 score was $1.7 \pm 1.0$. 


\section{Clinical Outcomes}

Seven important clinical outcomes in the setting of UGIB were evaluated. Blood transfusion was considered clinically necessary in almost three-quarters of the patients (321 patients; 74.1\%). The median number of red blood cell units transfused was 2 (IQR: 0-4). Attending physicians considered the bleeding episode sufficiently severe to require a close monitoring in an intensive or intermediate care unit in $46.2 \%$ of the cases (200 patients). The remaining patients were admitted to a conventional ward, with the exception of 13 patients who were discharged. The median length of hospital stay was 8 days (IQR: 6-11). During upper endoscopy, a therapeutic intervention was performed in 169 patients (39.0\%): 63 patients had a hemostatic procedure for variceal bleeding, while 106 patients had an intervention in the context of nonvariceal bleeding. Surgery was required as a rescue therapy in only 8 patients (1.8\%). Two of the most important outcomes that were analyzed were 30 -day rebleeding and mortality, which occurred in $33(7.6 \%)$ and in 32 (7.4\%) patients, respectively. From the patients who had rebleeding, only 6 died in the following 30 days. The median interval time from admission to rebleeding was 5.5 days (IQR: 3.0-8.5), while death occurred averagely 11.5 \pm 6.2 days after admission.

\section{Comparison between Scores}

When AUROCs of each score were compared, the sGBS and GBS were found to be the only scores that were good in predicting the need for blood transfusion, having AUROCs of 0.828 (95\% CI: 0.774-0.882) and 0.826 (95\% CI: 0.773-0.880), respectively. No statistical differences were found between them $(p=0.898)$. The 3 remaining scores were not useful in predicting this outcome. The sGBS and GBS were again the only scores that could fairly predict the need for surgery for bleeding control, presenting AUROCs of 0.736 (95\% CI: 0.588-0.885) and 0.706 (95\% CI: 0.564-0.848), respectively. Once again, the sGBS performed as well as the GBS with no statistically significant differences found between them $(p=$ 0.529).

Any of the 5 compared scores were able to predict the remaining clinical intervention-related outcomes, such as admission to intermediate or intensive care unit, length of hospital stay longer than 1 week, and need for therapeutic endoscopic intervention. While 30 -day rebleeding could not be accurately predicted by any of the studied scores, prediction of 30-day mortality was possible by the PreRS and PostRS, which presented AUROCs of 0.711 (95\% CI: 0.618-0.804) and 0.714 (95\% CI: 0.623-0.805),
Table 2. Baseline patient characteristics

\begin{tabular}{|c|c|}
\hline Median age (IQR), years & $67.8(56.0-80.0)$ \\
\hline \multicolumn{2}{|l|}{ Gender, $n(\%)$} \\
\hline Male & $281(64.9)$ \\
\hline Female & $152(35.1)$ \\
\hline \multicolumn{2}{|l|}{ Symptoms at admission, $n(\%)$} \\
\hline Melena & $200(46.2)$ \\
\hline Hematemesis & $188(43.4)$ \\
\hline Syncope & $49(11.3)$ \\
\hline Hematemesis and melena & $33(7.6)$ \\
\hline Hematochezia & $12(2.8)$ \\
\hline \multicolumn{2}{|l|}{ Comorbidities, $n(\%)$} \\
\hline Heart failure & $95(21.9)$ \\
\hline Liver disease & $85(19.6)$ \\
\hline Renal failure & $35(8.1)$ \\
\hline Ischemic heart disease & $34(7.9)$ \\
\hline Disseminated malignancy & $15(3.5)$ \\
\hline Other major comorbidity & $241(55.7)$ \\
\hline \multicolumn{2}{|l|}{ Medications, $n(\%)$} \\
\hline Acetylsalicylic acid & $120(27.7)$ \\
\hline Proton pump inhibitors & $119(27.5)$ \\
\hline Nonsteroidal anti-inflammatory drugs & $75(17.3)$ \\
\hline Anticoagulant agent & $75(17.3)$ \\
\hline Antiplatelet agents & $45(10.4)$ \\
\hline Steroids & $24(5.5)$ \\
\hline Selective serotonin reuptake inhibitors & $24(5.5)$ \\
\hline \multicolumn{2}{|l|}{ Physical findings, $n(\%)$} \\
\hline Tachycardia & $115(26.6)$ \\
\hline Shock & $71(16.4)$ \\
\hline Altered mental status & $41(9.5)$ \\
\hline \multicolumn{2}{|l|}{ Laboratory results, mean \pm SD } \\
\hline Hemoglobin, g/dL & $9.1 \pm 2.7$ \\
\hline Urea, mg/dL & $80.6 \pm 50.1$ \\
\hline Albumin, g/dL & $2.9 \pm 1.2$ \\
\hline INR & $1.6 \pm 1.2$ \\
\hline \multicolumn{2}{|l|}{ Findings at endoscopy, $n(\%)$} \\
\hline Gastric ulcer & $73(16.9)$ \\
\hline Esophageal varices & $66(15.2)$ \\
\hline Duodenal ulcer & $64(14.8)$ \\
\hline Esophagitis & $30(6.9)$ \\
\hline Gastritis & $27(6.2)$ \\
\hline Mallory-Weiss tear & $24(5.5)$ \\
\hline Neoplasia & $22(5.1)$ \\
\hline Angiectasia & $14(3.2)$ \\
\hline Gastric varices & $10(2.3)$ \\
\hline Dieulafoy lesion & $9(2.1)$ \\
\hline Gastric antral vascular ectasia & $2(0.5)$ \\
\hline Cameron lesion & $2(0.5)$ \\
\hline Portal hypertension gastropathy & $1(0.2)$ \\
\hline Other sources & $12(2.8)$ \\
\hline Normal endoscopy & $77(17.8)$ \\
\hline
\end{tabular}

$\mathrm{IQR}$, interquartile range; SD, standard deviation; INR, international normalized ratio. 

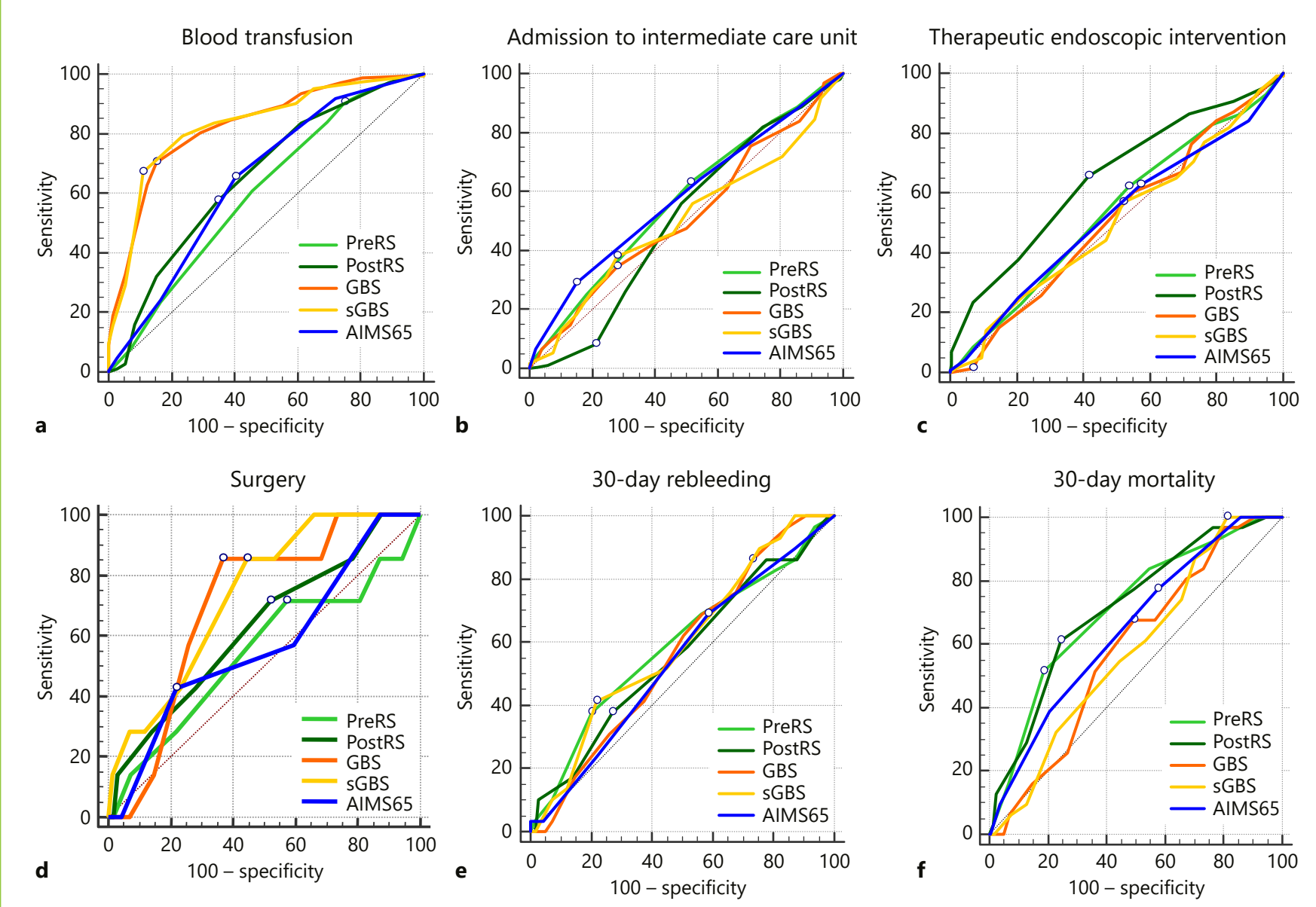

Fig. 1. ROC curve comparison of the PreRS, PostRS, GBS, sGBS, and AIMS65 for the prediction of blood transfusion (a), admission to the intermediate care unit (b), therapeutic endoscopic intervention (c), surgery (d), 30-day rebleeding (e), and 30-day mortality (f). ROC, receiver operating characteristic; PreRS, pre-endoscopic Rockall score; PostRS, postendoscopic Rockall score; GBS, Glasgow-Blatchford score; sGBS, simplified version of the Glasgow-Blatchford score. respectively. No differences between them were found $(p=0.915)$.

In this group of patients, the AIMS65 score was not able to accurately predict any of the 7 studied clinical outcomes. A comparison between the ROC curves of the 5 different scores in the abovementioned clinical outcomes can be seen in Figure 1.

\section{Discussion}

Several recent guidelines on UGIB state that early risk stratification should be a cardinal step in the assessment of patients in the ED $[4,5]$. The RS, the GBS, and more recently the AIMS65 score are some of the most used and cited scores. Nevertheless, since all available scores have some limitations and weaknesses that have not yet been overcome, the perfect risk score seems to be a long way away. In the meantime, a comparison between older risk scores, their simplified versions, and newer scores to assess their individual ability to predict each outcome is essential to guide evidence-based clinical decisions. While many authors have published studies comparing the older PreRS, PostRS, and GBS, few comparative studies have included the sGBS and the recent AIMS65 score.

The PostRS has the disadvantage of requiring endoscopic data, which can delay the risk assessment, particularly when after-hours emergency endoscopy is not avail- 
able, and also of including some difficult-to-define terms, namely "any major comorbidities," which may affect the correct score calculation. Regarding RS-predictable outcomes, while the initial study proposing the RS reported a good accuracy in predicting mortality and rebleeding [6], subsequent studies questioned its ability to predict rebleeding, suggesting the use of the RS for mortality prediction only $[12,13]$. This result was also observed in our study, in which the PostRS was good in predicting 30-day mortality but failed to predict rebleeding.

While a comparison of the PreRS and PostRS has been the common goal of many studies, the obtained results have been contradictory. While some authors suggested that the PreRS was not useful in predicting death when compared to the PostRS [14], others presented results admitting that the PreRS can be as good as the PostRS in predicting mortality $[15,16]$. In our cohort of patients, the PreRS and PostRS were the only scores which could accurately predict 30 -day mortality, exhibiting similar performances. This result is encouraging, suggesting that the PostRS may be replaced by the simpler PreRS.

Despite not requiring endoscopic data, the GBS has as well some features that may hamper its routine use in daily clinical practice. Firstly, it is composed of too many variables, with different weights, that might be difficult to recall in the stressful setting of the ED. Then, some of the included variables, in particular syncope, melena, hepatic disease, and heart failure, are subjective and ambiguous, potentially leading to an inaccurate and not always reproducible classification of patients. Syncope, for example, which is often not witnessed by health-care professionals, may not be adequately reported by confused patients or by stressed relatives. On the other hand, melena, which is defined as black tarry stool, may be confused with the expected discoloration of feces in patients taking oral iron supplements or bismuth-containing medications. Still, concerning the definition of heart failure, it is questionable if it should include only patients with decompensated disease or also with compensated disease or if there should be any established ejection fraction cutoff. Finally, regarding hepatic disease, it is dubious if only patients with signs of cirrhosis should be considered or if those with chronic liver disease but no signs of cirrhosis should be included as well. Regardless of these limitations, the GBS is of proven value in the initial assessment of patients with UGIB, and many studies have confirmed its capacity to accurately predict the need for medical intervention, even in specific subgroups of patients, such as cancer patients $[7,17,18]$. In our study, the GBS had a particularly good accuracy in predicting the need for blood transfusion, which was superior to the PreRS, PostRS, and AIMS65. This finding is concordant with other studies $[15,16,19]$ and might be explained by the fact that the GBS is the only score that uses hemoglobin for its calculation and because it is one of the most weighted variables within this score. As previously reported in other studies $[15,16]$, the GBS was also accurate in predicting the need for surgical treatment.

In order to facilitate the wide application of risk scores in the initial assessment of UGIB patients, a simplified version of the GBS has been proposed. Here, we aimed to analyze if the recently proposed sGBS had a performance similar to the original GBS. In the studied group of patients, we were able to confirm that, while overlapping with the GBS, the sGBS outperformed the PreRS, PostRS, and AIMS65 when predicting blood transfusion or surgery. This result is again in accordance with other authors [9], reinforcing the potential role of this simplified version when assessing a patient in the ED.

The AIMS65 score was recently created with the purpose of overcoming some limitations of previous scores by including equally weighted and easy-to-recall variables. It showed a great accuracy in predicting mortality and length of hospital stay when used generally in the UGIB setting, independently of the etiology [8]. However, some authors have questioned its usefulness in some particular subgroups of patients, namely those with peptic ulcer [20]. This may be explained by the fact that 3 from the 5 variables included in this score, such as albumin, mental status, and INR, are deeply associated with cirrhosis and variceal bleeding. While, in our study, the AIMS65 score has been the only score that could not accurately predict any of the studied outcomes, some reasons can be pointed out to explain this finding. First of all, serum albumin, unlike hemoglobin, urea, or INR, is not routinely analyzed in the ED of our center, precluding the calculation of the AIMS65 score in about one-quarter of the patients. Secondly, we included patients with both variceal and nonvariceal causes of bleeding, and, as stated before, the AIMS65 might be useless in some subgroups of patients. Finally, we reached some conclusions which are in accordance with other studies, namely the inability of the AIMS65 score to accurately predict blood transfusion, rebleeding, or admission to the intensive/intermediate care unit [21].

Regarding UGIB, there is currently a growing interest in not only optimizing and simplifying the existing risk scores but also in creating new, more accurate ones. As an unique score applicable to all cases of UGIB, independently of the etiology, and capable of predicting with precision 


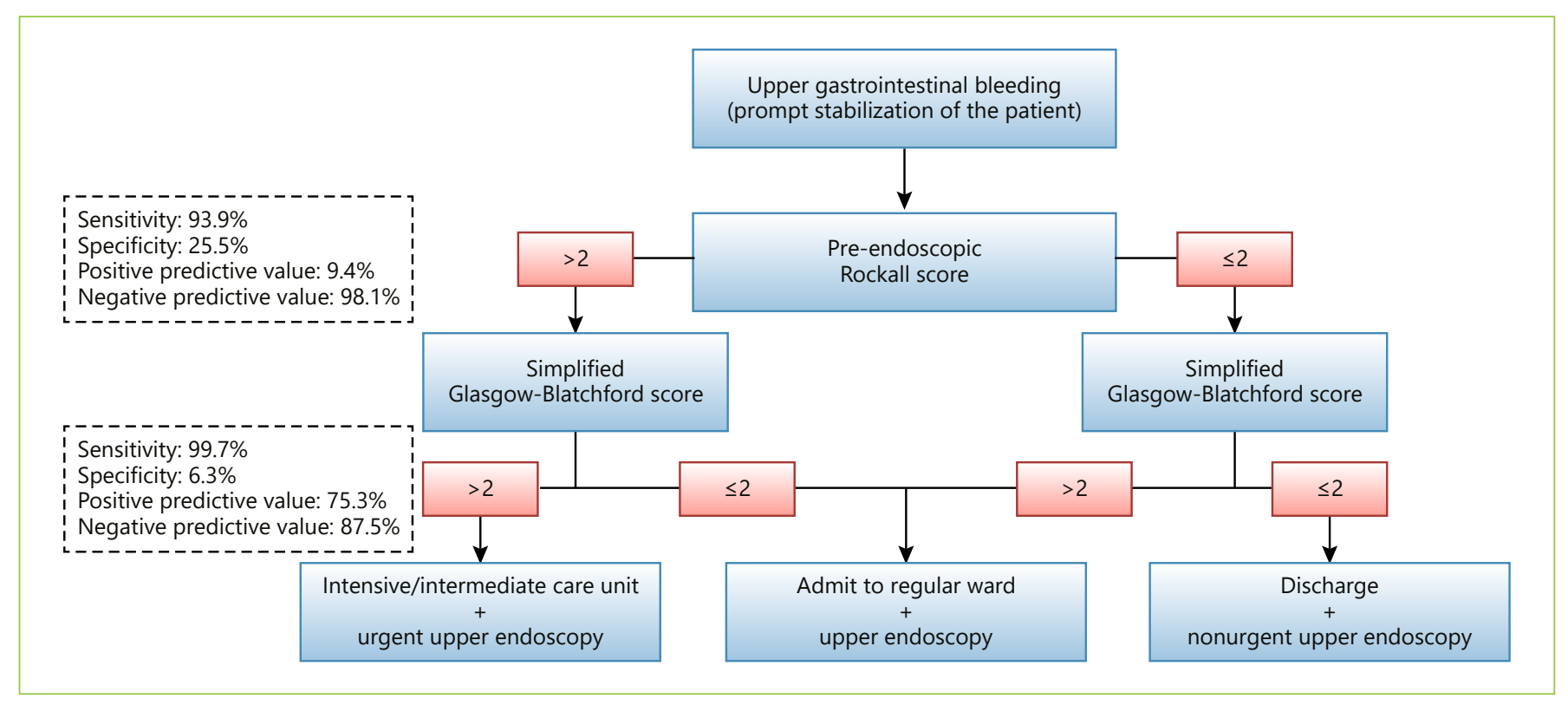

Fig. 2. Proposed algorithm for risk assessment in the upper gastrointestinal bleeding setting.

all the relevant clinical outcomes is not yet available, we admit that the combination of a few simple risk scores might be useful for physicians assessing patients with UGIB in the ED, particularly when emergency endoscopy is not available on a 24 -h basis. Bearing this idea in mind, we attempted to provide an easy-to-follow algorithm to readily guide decisions (Fig. 2). We propose that the initial calculation of the PreRS, which does not require endoscopic data, contains only 3 clinical parameters and can assess the risk of mortality as accurately as the PostRS. The definition of 2 as the cutoff allows this model to have a sensitivity of $93.9 \%$ and a negative predictive value of $98.1 \%$. The next step should be the calculation of the sGBS. This score has the advantage of abolishing the subjective parameters of the original GBS, such as syncope, melena, heart failure, and hepatic disease, while performing equally well in predicting medical intervention. Once again, the establishment of 2 as the cutoff allowed a high sensitivity (99.7\%) and negative predictive value (87.5\%). According to our proposed algorithm, the use of these 2 risk scores, the PreRS and the sGBS, should dictate the degree of medical care and the time until upper endoscopy.

To the best of our knowledge, this is the first published study comparing the PreRS, PostRS, GBS, sGBS, and AIMS65 scores. We showed that none of the 5 studied scores can be singly used to predict the clinically relevant outcomes in the setting of UGIB: blood transfusion, endoscopic therapeutic intervention, surgery, admission to intensive/intermediate care unit, length of hospital stay, rebleeding, and death. The PreRS and PostRS were the only scores that could predict 30 -day mortality. In addition, the sGBS is as precise as its original version in predicting blood transfusion and surgery. On the contrary, any of the 5 scores is sufficiently accurate in predicting endoscopic therapy or rebleeding. While a novel simpler score is not available and validated for the prediction of all outcomes in undifferentiated UGIB (either variceal or nonvariceal), we propose the concomitant use of the PreRS and sGBS as part of the initial assessment of these patients.

\section{Statement of Ethics}

The study was approved by the local ethics committee. Since the study was retrospective and the study subjects were anonymized, the ethical committee waived the necessity for written consent from the patients.

\section{Disclosure Statement}

The authors have no conflicts of interest to declare.

\section{Funding Sources}

No funding was received for this study. 
1 Longstreth GF: Epidemiology of hospitalization for acute upper gastrointestinal hemorrhage: a population-based study. Am J Gastroenterol 1995;90:206-210.

-2 Terdiman JP: Update on upper gastrointestinal bleeding. Basing treatment decisions on patients' risklevel. Postgrad Med 1998;103:4347, 51-52, 58-59 passim.

-3 van Leerdam ME, Vreeburg EM, Rauws EA, Geraedts AA, Tijssen JG, Reitsma JB, Tytgat GN: Acute upper GI bleeding: did anything change? Time trend analysis of incidence and outcome of acute upper GI bleeding between 1993/1994 and 2000. Am J Gastroenterol 2003;98:1494-1499.

-4 Barkun AN, Bardou M, Kuipers EJ, Sung J, Hunt RH, Martel M, Sinclair P; International Consensus Upper Gastrointestinal Bleeding Conference Group: International consensus recommendations on the management of patients with nonvariceal upper gastrointestinal bleeding. Ann Intern Med 2010;152:101-113.

5 Laine L, Jensen DM: Management of patients with ulcer bleeding. Am J Gastroenterol 2012;107:345-360; quiz 361.

6 Rockall TA, Logan RF, Devlin HB, Northfield TC: Risk assessment after acute upper gastrointestinal haemorrhage. Gut 1996;38:316321.

7 Blatchford O, Murray WR, Blatchford M: A risk score to predict need for treatment for upper-gastrointestinal haemorrhage. Lancet 2000;356:1318-1321.

8 Saltzman JR, Tabak YP, Hyett BH, Sun X, Travis AC, Johannes RS: A simple risk score accurately predicts in-hospital mortality, length of stay, and cost in acute upper GI bleeding. Gastrointest Endosc 2011;74:1215-1224.
\$9 Cheng DW, Lu YW, Teller T, Sekhon HK, Wu BU: A modified Glasgow Blatchford Score improves risk stratification in upper gastrointestinal bleed: a prospective comparison of scoring systems. Aliment Pharmacol Ther 2012;36:782-789.

10 Nakamura S, Matsumoto T, Sugimori H, Esaki M, Kitazono T, Hashizume M: Emergency endoscopy for acute gastrointestinal bleeding: prognostic value of endoscopic hemostasis and the AIMS65 score in Japanese patients. Dig Endosc Society 2014;26:369-376.

11 Hanley JA, McNeil BJ: A method of comparing the areas under receiver operating characteristic curves derived from the same cases. Radiology 1983;148:839-843.

12 Kim BJ, Park MK, Kim SJ, Kim ER, Min BH, Son HJ, Rhee PL, Kim JJ, Rhee JC, Lee JH: Comparison of scoring systems for the prediction of outcomes in patients with nonvariceal upper gastrointestinal bleeding: a prospective study. Dig Dis Sci 2009;54:25232529.

13 Church NI, Dallal HJ, Masson J, Mowat NA, Johnston DA, Radin E, Turner M, Fullarton G, Prescott RJ, Palmer KR: Validity of the Rockall scoring system after endoscopic therapy for bleeding peptic ulcer: a prospective cohort study. Gastrointest Endosc 2006;63:606-612.

14 Custodio Lima J, Garcia Montes C, Kibune Nagasako C, Soares Ruppert Reis GF, Meirelles Dos Santos JO, Guerrazzi F, Mesquita MA: Performance of the Rockall scoring system in predicting the need for intervention and outcomes in patients with nonvariceal upper gastrointestinal bleeding in a Brazilian setting: a prospective study. Digestion 2013;88:252-257.
15 Stanley AJ, Dalton HR, Blatchford O, Ashley D, Mowat C, Cahill A, Gaya DR, Thompson E, Warshow U, Hare N, Groome M, Benson G, Murray W: Multicentre comparison of the Glasgow Blatchford and Rockall scores in the prediction of clinical end-points after upper gastrointestinal haemorrhage. Aliment Pharmacol Ther 2011;34:470-475.

16 Bryant RV, Kuo P, Williamson K, Yam C, Schoeman MN, Holloway RH, Nguyen NQ: Performance of the Glasgow-Blatchford score in predicting clinical outcomes and intervention in hospitalized patients with upper GI bleeding. Gastrointest Endosc 2013;78:576583.

17 Laursen SB, Hansen JM, Schaffalitzky de Muckadell OB: The Glasgow Blatchford score is the most accurate assessment of patients with upper gastrointestinal hemorrhage. Clin Gastroenterol Hepatol 2012;10:1130-1135. e1131.

18 Ahn S, Lim KS, Lee YS, Lee JL: Blatchford score is a useful tool for predicting the need for intervention in cancer patients with upper gastrointestinal bleeding. J Gastroenterol Hepatol 2013;28:1288-1294.

19 Dicu D, Pop F, Ionescu D, Dicu T: Comparison of risk scoring systems in predicting clinical outcome at upper gastrointestinal bleeding patients in an emergency unit. Am J Emerg Med 2013;31:94-99.

20 Jung SH, Oh JH, Lee HY, Jeong JW, Go SE, You CR, Jeon EJ, Choi SW: Is the AIMS65 score useful in predicting outcomes in peptic ulcer bleeding? World J Gastroenterol 2014;20:1846-1851.

21 Hyett BH, Abougergi MS, Charpentier JP, Kumar NL, Brozovic S, Claggett BL, Travis AC, Saltzman JR: The AIMS65 score compared with the Glasgow-Blatchford score in predicting outcomes in upper GI bleeding. Gastrointest Endosc 2013;77:551-557. 